\title{
Sorption Characteristics of Hexavalent Chromium in the Soil Based on Batch Experiment and Their Implications to the Environment
}

\author{
Muhajir M. Kwikima, Meserecordias W. Lema \\ College of Earth Sciences, University of Dodoma, Dodoma, Tanzania \\ Email: drlemaofficial@gmail.com
}

How to cite this paper: Kwikima, M.M. and Lema, M.W. (2017) Sorption Characteristics of Hexavalent Chromium in the Soil Based on Batch Experiment and Their Implications to the Environment. Journal of Geoscience and Environment Protection, 5, 152-164.

https://doi.org/10.4236/gep.2017.53011

Received: February 15, 2017

Accepted: March 26, 2017

Published: March 29, 2017

Copyright $\odot 2017$ by authors and Scientific Research Publishing Inc. This work is licensed under the Creative Commons Attribution International License (CC BY 4.0).

http://creativecommons.org/licenses/by/4.0/

\begin{abstract}
The objective of this experimental study was to determine the kinetics and equilibrium sorption of $\mathrm{Cr}(\mathrm{VI})$ in soils collected from Hengshui City of Hebei Province, China, based on batch experiments. The main concentration for this paper is on the effect of soil $\mathrm{pH}$, solute concentration and ionic strength as the variable factors in the sorption of $\mathrm{Cr}(\mathrm{VI})$ in soils and the assessment of their implications to the environment. Atomic Absorption Spectrophotometer (AAS) was used for $\mathrm{Cr}$ (III) analysis; UV-VIS Spectrophotometer for quantification of $\mathrm{Cr}(\mathrm{VI})$ in soil samples and determination of electrical conductivity and temperature of the soil samples; and Automatic Laser Particle Size Analyzer LS230 for the determination of soil physical characteristics. Results from this study show that adsorption and reduction are major reactions accounting for removal of $\mathrm{Cr}(\mathrm{VI})$ from soil solution. It is concluded that chemical reactions such as reduction, strongly influence $\mathrm{Cr}(\mathrm{VI})$ mobility in soil. Adsorption kinetics experiments indicated that $\mathrm{Cr}(\mathrm{VI})$ removal from soil solution increases with increasing solute concentration, with decreasing $\mathrm{pH}$ and with decreasing ionic strength. Adsorption reactions reached equilibrium within 12 hours in batch reactors. Increasing background electrolyte concentration (KCI) decreases $\mathrm{Cr}(\mathrm{VI})$ adsorption on soil. The $\mathrm{Cr}(\mathrm{VI})$ adsorption isotherm for this soils conforms well to the Langmuir isotherm at constant $\mathrm{pH}$. Two $\mathrm{Cr}(\mathrm{VI})$ adsorption parameters: the maximum sorption capacity $\left(\mathrm{Q}_{\mathrm{o}}\right)$ and Langmuir adsorption constant $\left(\mathrm{K}_{\mathrm{L}}\right)$, were determined as $1.0135 \times 10^{-4} \mathrm{~mol} / \mathrm{g}$ and $0.0622 \mathrm{mg} / \mathrm{L}$, respectively. The reduction of $\mathrm{Cr}(\mathrm{VI})$ into less toxic $\mathrm{Cr}(\mathrm{III})$, means reduction of significant environmental problems. Finally, this study advises relevant environmental governing authorities to observeperiodic monitoring of the status of $\mathrm{Cr}(\mathrm{VI})$ in soils.
\end{abstract}




\section{Keywords}

Soil, Hexavalent Chromium, Reduction, Adsorption

\section{Introduction}

Chromium (Cr) is the seventh most abundant element on earth [1]. It exists in oxidation states ranging from 0 , II, III, IV, V to VI, in which only two of them; $\mathrm{Cr}(\mathrm{III})$ and $\mathrm{Cr}(\mathrm{VI})$ are stable enough to occur in the environment [1] [2]. $\mathrm{Cr}$ (II), $\mathrm{Cr}(\mathrm{IV})$, and $\mathrm{Cr}(\mathrm{V})$ are unstable forms, and very little information is available about their hydrolysis [1] [2] [3]. Chromium is a ubiquitous contaminant of soils and groundwater, and is derived from both natural and anthropogenic sources [3]. Chromium compounds have various industrial applications, including chromium plating, metallurgy, pigment manufacturing, tanning and wood preservation [4]-[10]. Often wastes from such industries (i.e. sludge, fly ash and slag) are used as fill materials at numerous locations to reclaim marshlands, for tank dikes, and for backfill at sites following demolition [7]. Chromium manufacturing industries produce a large quantity of solid and liquid wastes containing hexavalent chromium. At many such sites, leaching and seepage of $\mathrm{Cr}(\mathrm{VI})$ from the soils into the groundwater pose a considerable health hazard to both plants and animals (including humans) [5]-[10]. Although both $\mathrm{Cr}(\mathrm{III})$ and $\mathrm{Cr}(\mathrm{VI})$ are the stable oxidation states of chromium in the environment, $\mathrm{Cr}(\mathrm{VI})$ is of particular concern due to its extreme toxicity (100 - 1000 times higher than that of $\mathrm{Cr}$ (III) [8] [9]. Due to its high solubility and adverse health effects, $\mathrm{Cr}(\mathrm{VI})$ poses a significant environmental hazard [11]. The treatment of these wastes is essential before discharging them to the environment. $\mathrm{Cr}(\mathrm{VI})$ compounds are highly water soluble, toxic and carcinogenic in mammals [5] [11]. In contrast, trivalent chromium is considered to be non-toxic as it precipitates at $\mathrm{pH}$ higher than 5.5 with the formation of insoluble oxides and hydroxides in soil and water systems [10] [11] [12].

Chromium, in its trivalent form ( $\mathrm{Cr}(\mathrm{III})$ ), is an important component of a balanced human and animal diet and its deficiency causes disturbance to the glucose and lipids metabolism in humans and animals [5] [11] [14]. In contrast, Hexavalent $\mathrm{Cr}(\mathrm{VI})$ is highly toxic (carcinogenic) and may cause death to animals and humans if ingested in large doses [13] [14] [15]. Recently, concern about chromium as an environmental pollutant has been escalating due to its build-up to toxic levels in the environment as a result of various industrial and agricultural activities [13]. Most research has been done to investigate the impacts of chromium on crops/plants [14] [15]. According to Sharma et al. [14], the toxic effects of chromium on plant growth and development include alterations in the germination process as well as in the growth of roots, stems and leaves, which may affect total dry matter production and yield. For example, it was reported that chromium caused visible lesions of interveinal chlorosis in maize (Zea mays) while plant physiological processes such as photosynthesis, water relations 
and mineral nutrition were reported to be adversely affected [15]. Metabolic alterations in plants following chromium exposure could either be due to a direct effect on various enzymes or other metabolites or because of its ability to generate reactive oxygen species (ROS), which may cause oxidative stress [16] [17] [18].

All over the world, soil is regarded as the key element to human survival and can be described by various definitions according to its main utility. Heavy metals are natural constituents of rocks and soils in concentrations that do not represent any risk to animal or plants [14] [15] [16] [17] [18]. Some anthropogenic activities like the spreading of sewage sludge or fertilizers, the discharge of domestic and industrial effluents in land as well as atmospheric disposal, promote augmentation of these metals' concentrations to toxic levels. For example, tanning industry is, especially, a large contributor of $\mathrm{Cr}$ pollution to water resources [4] [19]. Chandra et al. [19] estimated that in India alone about 2000 to 3200 tons of elemental $\mathrm{Cr}$ escape into the environment annually from tanning industries, with $\mathrm{Cr}$ concentrations ranging between 2000 and $5000 \mathrm{mg} \cdot \mathrm{L}^{-1}$ in the effluent compared to the recommended permissible limit of $2 \mathrm{mg} \cdot \mathrm{L}^{-1}$ [5] [11].

Being one of the fastest growing economy, China is also encountering problems of soil pollution from heavy metals (chromium inclusive) [20] [21]. This is mostly accelerated with rapid expansion and increase in industrial development [22]. It is therefore the main objective of this research to study sorption characteristics of hexavalent chromium in the soils of China (Hengshui City of Hebei Province) based on batch experiment and determination of the associated possible environmental impacts.

\section{Materials and Methods}

\subsection{Materials and Reagents}

The main type of materials used in this study was soil from Hengshui City of Hebei Province, China. Concentrated hydrochloric acid was used for the determination of Total Inorganic Carbon Content (TIC) of soil; concentrated sulfuric acid, potassium hydrogen phthalate and dichromate reagent for the determination of soil reduction capacity; and ammonium oxalate and dithionitecitratebicarbonate (DCB) for the determination of reduced $\mathrm{Cr}(\mathrm{VI})$ in soil.

\subsection{Equipment}

The following laboratory equipment were used in this study; constant-temperature shaker bath for mixing soil suspensions, Atomic Absorption Spectrophotometer (AAS) for $\mathrm{Cr}$ (III) analysis, UV-VIS Spectrophotometer for quantification of $\mathrm{Cr}(\mathrm{VI})$ in soil samples and determination of electrical conductivity and temperature of the soil samples, Automatic Laser Particle Size Analyzer LS230 for determination of soil physical characteristics.

\subsection{The Batch Experiments}

Batch experiments were conducted to determine adsorption kinetics of $\mathrm{Cr}(\mathrm{VI})$ in 
the soil with the influence of $\mathrm{pH}$, solute concentration and ionic strength. These experiments also involved development of equilibrium adsorption isotherms from which soil maximum adsorption capacity and adsorption coefficient were determined. Furthermore, data on the removal of hexavalent chromium from soils were obtained from this study's batch experiments

\subsection{Experimental Setup}

Batch experiments were conducted in completely mixed reactors in a temperature-controlled room $\left(25^{\circ} \mathrm{C} \pm 3^{\circ} \mathrm{C}\right)$. Adsorption and desorption experiments were run to determine kinetics and equilibrium sorption and desorption parameters of $\mathrm{Cr}(\mathrm{VI})$ on soil samples. All batch experiments were conducted under oxic conditions.

\subsection{Adsorption Kinetics}

Short-term and long-term kinetics experiments were used to determine the time required for $\mathrm{Cr}(\mathrm{VI})$ to approach equilibrium during sorption and desorption. For short-term and long-term adsorption kinetics, identical reactor tubes were left on the shaker bath at varying $\mathrm{pH}$ values and for various times, ranging from 1 to 24 hours and 1 to 120 hours, respectively. Adsorption experiments were conducted in $100 \mathrm{ml}$, screw-top plastic centrifuge tubes. The soil ( 2.5 grams) was reacted with $50 \mathrm{ml}$ of a solution. Hexavalent chromium was added to yield concentrations ranging between $1 \times 10^{-1}$ and $5 \times 10^{-2} \mathrm{M}$. The $\mathrm{pH}$ was adjusted by adding various volumes of $1.0 \mathrm{M} \mathrm{HCl}$ and $\mathrm{NaOH}$. Soil suspensions were mixed through continuous shaking in a $25^{\circ} \mathrm{C}$ constant-temperature shaker bath. After mixing for the desired reaction time, the suspensions were centrifuged at 4000 rpm for 10 minutes and the supernatant solutions were passed through $0.45 \mu \mathrm{m}$ millipore filters. Chromium concentrations in the supernatant solutions were determined by EPA 7196 Method [23] and adsorbed chromium was determined by the differences between the initial and final solution concentrations. The $\mathrm{pH}$ of each sample was also determined.

\subsection{Adsorption Isotherms}

Adsorption isotherms were determined in completely-mixed batch reactors in a temperature-controlled chamber. The soil suspensions were then prepared with 2.5 grams of soil and $50 \mathrm{ml}$ of $0.01 \mathrm{M}$ of $\mathrm{KCl}$ background electrolyte solution. $\mathrm{Cr}(\mathrm{VI})$ was added to yield ten concentrations ranging from $5 \times 10^{-5} \mathrm{M}$ to $5 \times$ $10^{-4} \mathrm{M}$, and equilibrated at $25^{\circ} \mathrm{C}$, constant temperature. After 120 hours equilibration time, suspensions were centrifuged and the dissolved chromium and $\mathrm{pH}$ were determined as described in the adsorption kinetic experiments. The effects of varying $\mathrm{pH}$ values and supporting electrolyte concentrations was also determined on $\mathrm{Cr}(\mathrm{VI})$ equilibrium isotherms.

\subsection{Soil Pre-Treatment and Analysis}

Wet soil samples collected from the field were kept in an open space (inside the 
laboratory facility) for about two weeks to allow them dry by normal atmospheric air. The air-dried samples were then grinded and mixed well, and later on passed through a $2 \mathrm{~mm}$ stainless steel sieve to obtain a homogeneous sample. These samples were finally kept in plastic bags, ready for further analysis. $\mathrm{pH}$ of the soil samples were determined using $\mathrm{pH}$ meter (1:1 soil/water suspension method) and the determination of hexavalent chromium in the soil was determined by Colorimetric Method [23]. UV-VIS Spectrophotometer [24] was used for quantification of $\mathrm{Cr}(\mathrm{VI})$ as well as the determination of electrical conductivity and temperature of the soil samples (Table 1 ). The other portion of untreated soil samples were used to determine soil physical characteristics (Table 2) by using Automatic Laser Particle Size Analyzer LS230 [25].

\section{Results and Discussion}

\subsection{Cr(IV) Adsorption Kinetics}

Figure 1 shows hexavalent chromium removal from solution at different solute concentrations as a function of time. Removal of hexavalent chromium from solution showed a rapid initial uptake followed by very slow uptake kinetics. At around 24 hours the process started to approach equilibrium and attained maximum within 48 hours, almost for all three concentrations $(0.26,0.52$ and 1.04 $\mathrm{mg} / \mathrm{L}$ ). Similar results were found for all kinetics of ionic strength and $\mathrm{pH}$ values as it can be seen on Figure 2 and Figure 3. Results of $\mathrm{Cr}(\mathrm{Vl})$ adsorption kinetics

Table 1. Soil chemical characterization experiment.

\begin{tabular}{ccc}
\hline Parameter & Values & Method \\
\hline pH & 8.67 & Soil: Water Soil Titration \\
Electrical Conductivity & $300.8 \mu \mathrm{S} / \mathrm{cm}$ & Soil: Water Soil Titration \\
Chromium VI & $0.005 \mathrm{mg} / \mathrm{L}$ & EPA: 7196A \\
Total chromium & $0.087 \mathrm{mg} / \mathrm{L}$ & Atomic Absorption (FAAS) \\
Moisture content & $0.94 \%$ & Oven at $105^{\circ} \mathrm{C}$ \\
Soil Temperature & $29{ }^{\circ} \mathrm{C}$ & Thermometer \\
Organic Content (TOC) & $2.32(\%)$ & Carbon Analyzer \\
Calcium & $1473(\mathrm{mg} / \mathrm{kg})$ & Ammonium Acetate \\
Magnesium & $102(\mathrm{mg} / \mathrm{kg})$ & Ammonium Acetate \\
Potassium & $364(\mathrm{mg} / \mathrm{kg})$ & Ammonium Acetate \\
Phosphate & $10.1(\mathrm{mg} / \mathrm{kg})$ & Ion Chromatography \\
Sulfate & $15(\mathrm{mg} / \mathrm{kg})$ & Ion Chromatography \\
Nitrate & $20.2(\mathrm{mg} / \mathrm{kg})$ & Ion Chromatography \\
Soluble Iron & $483(\mathrm{mg} / \mathrm{L})$ & DTPA \\
Soluble Manganese & $12.5(\mathrm{mg} / \mathrm{L})$ & DTPA
\end{tabular}

Table 2. Soil physical characterization.

\begin{tabular}{ccc}
\hline Physical & Percentage & Method \\
\hline Silt & 74 & LS230 \\
Clay & 20 & LS230 \\
Sand & 6 & LS230 \\
\hline
\end{tabular}




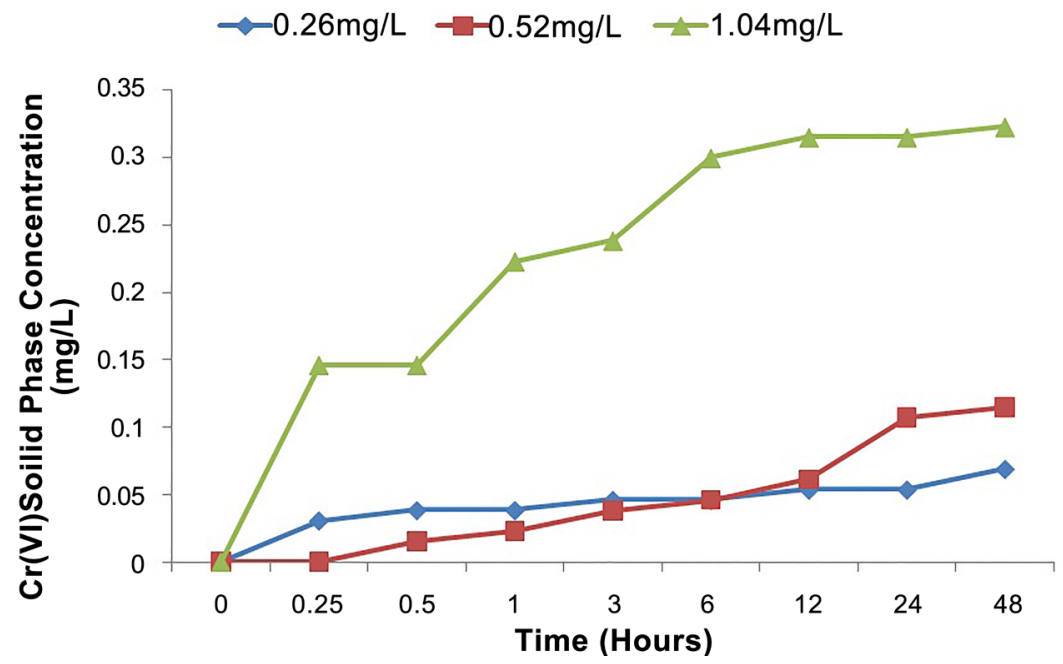

Figure 1. The effect of solute concentration on $\mathrm{Cr}(\mathrm{VI})$ adsorption kinetics in the soil.

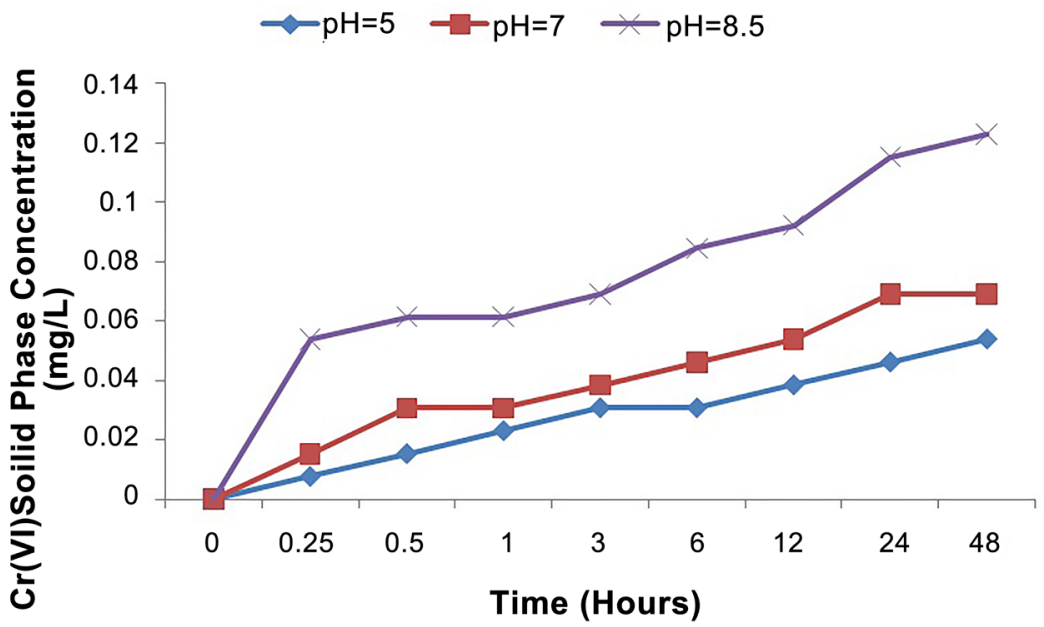

Figure 2. The effect of $\mathrm{pH}$ on $\mathrm{Cr}(\mathrm{VI})$ adsorption kinetics in the soil at constant solute concentration of $0.26 \mathrm{mg} / \mathrm{L}$ of $\mathrm{Cr}(\mathrm{VI})$.

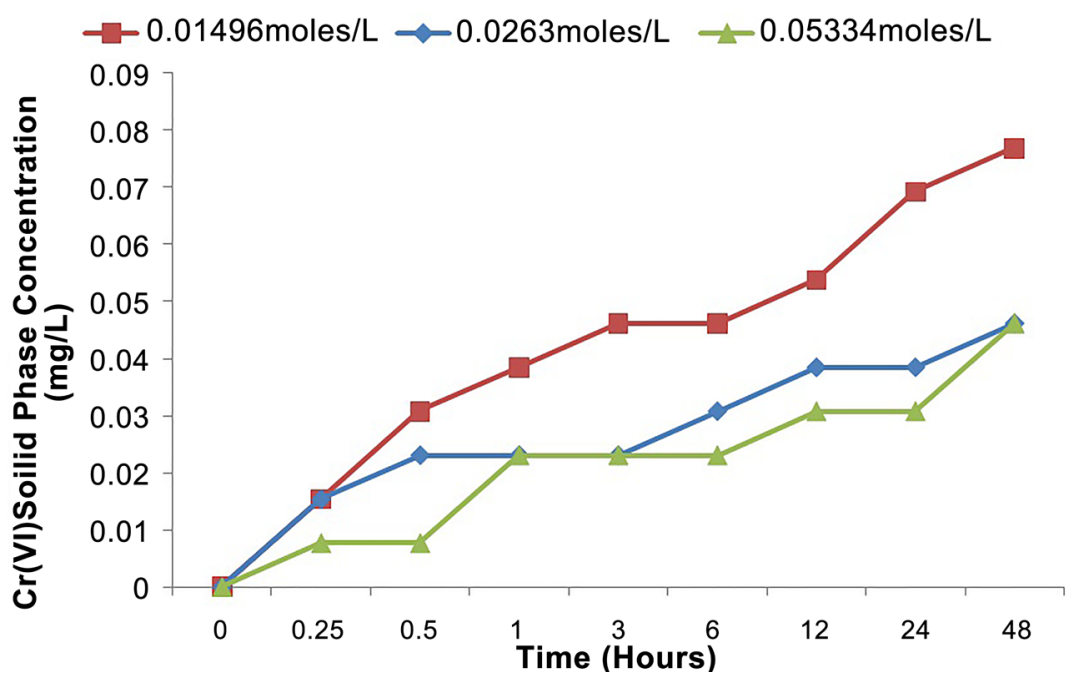

Figure 3. The effect of ionic strength $(0.001 \mathrm{MKCl})$ on $\mathrm{Cr}(\mathrm{VI})$ adsorption kinetics at constant solute concentration of $0.26 \mathrm{mg} / \mathrm{L} \mathrm{Cr}(\mathrm{VI})$. 
showed that the equilibrium was approached within 48 hours reaction time. Adsorption kinetics of $0.26 \mathrm{mg} / \mathrm{L} \mathrm{Cr}(\mathrm{Vl})$ as a function of time and at $\mathrm{pH}$ values of 5.20, 6.70 and 8.4 are demonstrated by plots of solid phase concentration against time (Figure 2). As Figure 2 shows, adsorption increases with increasing $\mathrm{pH}$. Adsorption kinetics of $0.26 \mathrm{mg} / \mathrm{L} \mathrm{Cr}(\mathrm{Vl})$ as a function of time are shown in Figure 3 showing the effect of ionic strength. Figure 3 shows the effect of $\mathrm{Cr}(\mathrm{VI})$ reduction on $\mathrm{Cr}(\mathrm{VI})$ adsorption kinetics experiment at concentration of 1.04 $\mathrm{mg} / \mathrm{L} \mathrm{Cr}(\mathrm{VI}), 2.5 \mathrm{~g}$ of soil.

Chromium (VI) removal process is termed as a more time dependent removal. The kinetics of chromium removal in this study indicates that equilibrium was not achieved until after 48 hours reaction time (Figures 1-3). Cameron and Klute [26] explained such adsorption of solute to soils by a combination of equilibrium and kinetic models. These models incorporate a rapid reaction site which equilibrates instantaneously with adsorbate and a slow reaction site [27]. He described such a removal process as a physical non-equilibrium phenomenon. Our experiments showed that over the $\mathrm{pH}$ range considered, the $\mathrm{Cr}(\mathrm{VI})$ removal process exhibits a di-phasic behavior with time (Figure 2). An initial, rapid, short-term uptake (phase I) of chromium (Vl) is followed by a long-term, slower uptake (phase II). Reduction of $\mathrm{Cr}(\mathrm{VI})$ to $\mathrm{Cr}(\mathrm{III})$ was the suspected cause for slow $\mathrm{Cr}(\mathrm{VI})$ removal from solution and experimentally it was necessary to distinguish adsorption of $\mathrm{Cr}(\mathrm{VI})$ from $\mathrm{Cr}(\mathrm{VI})$ reduction to $\mathrm{Cr}(\mathrm{III})$.

Although studies [28] [29] [30] have found Phosphate $\left(\mathrm{KH}_{2} \mathrm{PO}_{4} / \mathrm{K}_{2} \mathrm{HPO}_{4}\right)$ to be the best extracting agent for adsorbed $\mathrm{Cr}(\mathrm{VI})$ in soils, this study has shown that $\mathrm{Cr}(\mathrm{VI})$ reduction to $\mathrm{Cr}(\mathrm{III})$ is the major cause of $\mathrm{Cr}(\mathrm{VI})$ removal from the soils. Chromium extracted from the soil by $0.5 \mathrm{M}$ phosphate solution at $\mathrm{pH}$ about 8 was defined as the adsorbed fraction. Thus, any chromium that was not extracted was assumed to be reduced to $\mathrm{Cr}(\mathrm{llll})$ which was immobile in the soil as a precipitate of $\mathrm{Cr}(\mathrm{OH})_{3}$ (phase I) [31]. $\mathrm{Cr}(\mathrm{VI})$ adsorption was completed within 24 hours (Figure 1). $\mathrm{Cr}(\mathrm{VI})$ removal at longer reaction time (phase II) can be attributed to $\mathrm{Cr}(\mathrm{VI})$ reduction to $\mathrm{Cr}(\mathrm{III})$. It was concluded that phase I was largely due to diffusional transport and adsorption, as has been noted for the adsorption of $\mathrm{Cr}(\mathrm{Vl})$ on soil [32], while phase II was largely due to reduction of $\mathrm{Cr}(\mathrm{VI})$ to $\mathrm{Cr}(\mathrm{III})$.

\subsubsection{Effect of $\mathrm{Cr}(\mathrm{VI})$ Concentration on Adsorption Kinetics}

Chromium (VI) adsorption kinetics show that adsorption rate increased with increasing $\mathrm{Cr}(\mathrm{VI})$ concentration (Figure 1). Increased $\mathrm{Cr}(\mathrm{VI})$ uptake kinetics on the soil as $\mathrm{Cr}(\mathrm{VI})$ solution concentration increased is consistent with an adsorption removal mechanism because the rate of reaction is proportional to the concentration of the $\mathrm{Cr}(\mathrm{VI})$ solution [31].

\subsubsection{Effect of $\mathrm{pH}$ on $\mathrm{Cr}(\mathrm{VI})$ Adsorption Kinetics}

Chromium (VI) adsorption kinetics increased with decreasing solution $\mathrm{pH}$ (Figure 2). This is in agreement with the findings of Griffin et al. [33]. This can be explained by an increase in positive surface charges or electrostatic potential 
on soil particles with decreasing $\mathrm{pH}$, resulting in more adsorption sites available for $\mathrm{Cr}(\mathrm{VI})$. Increasing adsorption sites increase $\mathrm{Cr}(\mathrm{VI})$ adsorption rate because the rate of reaction between the solution and adsorbent is proportional to the concentration of the reactants. Similar results were obtained by James and Bartlett [34] for adsorption of $\mathrm{Cr}(\mathrm{VI})$ by various soils and $\mathrm{Fe}(\mathrm{OH})_{3}$.

\subsection{Chromium (VI) Adsorption Isotherms}

Figure 4 shows an adsorption isotherm in which the effects of $\mathrm{Cr}(\mathrm{Vl})$ reduction are included. The dependence of the amount of $\mathrm{Cr}(\mathrm{Vl})$ adsorption at constant $\mathrm{pH}$ and different solution concentration of $\mathrm{Cr}(\mathrm{Vl})$ is illustrated by the curves in Figure 4. The adsorption isotherms for this soil conformed to the Langmuir equation [35]. Two $\mathrm{Cr}(\mathrm{Vl})$ sorption parameters; the maximum sorption capacity $\left(\mathrm{Q}_{0}\right)$ and Langmuir adsorption constant $(\mathrm{K}$,$) were determined in 48$ hours isotherm experiments. Table 3 below reports the maximum adsorption capacity and Langmuir constant of $\mathrm{Cr}(\mathrm{Vl})$ equilibrium sorption at $\mathrm{pH}$ values from 7.5 to 8.00 .

Adsorption isotherms were developed for $\mathrm{Cr}(\mathrm{VI})$ adsorption on the experimental soil after 100 hours reaction time by excluding reduced $\mathrm{Cr}$ (III) from total chromium removal. Figure 4 shows that the equilibrium adsorption of $\mathrm{Cr}(\mathrm{VI})$ on a natural soil conformed well to the Langmuir isotherm at constant $\mathrm{pH}$. Similar results have been noted [32] [33] [36] for the adsorption of chromate on clay minerals, natural soils, and goethite, respectively. The maximum sorption capacity at $\mathrm{pH}$ of 8 was $1.527 \mathrm{mg} / \mathrm{L}$ soil solution. This value was lower than the maximum adsorption capacities reported by Zachara et al. [32], for the adsorption of

Table 3. Langmuir adsorption constant and maxima calculated from equilibrium isotherms.

\begin{tabular}{cc}
\hline Langmuir coefficient KL $(\mathrm{mg} / \mathrm{L})$ & Maximum adsorption capacity Qo (mol/g) \\
\hline 0.0622 & $1.0135 \times 10^{-4}$ \\
\hline
\end{tabular}

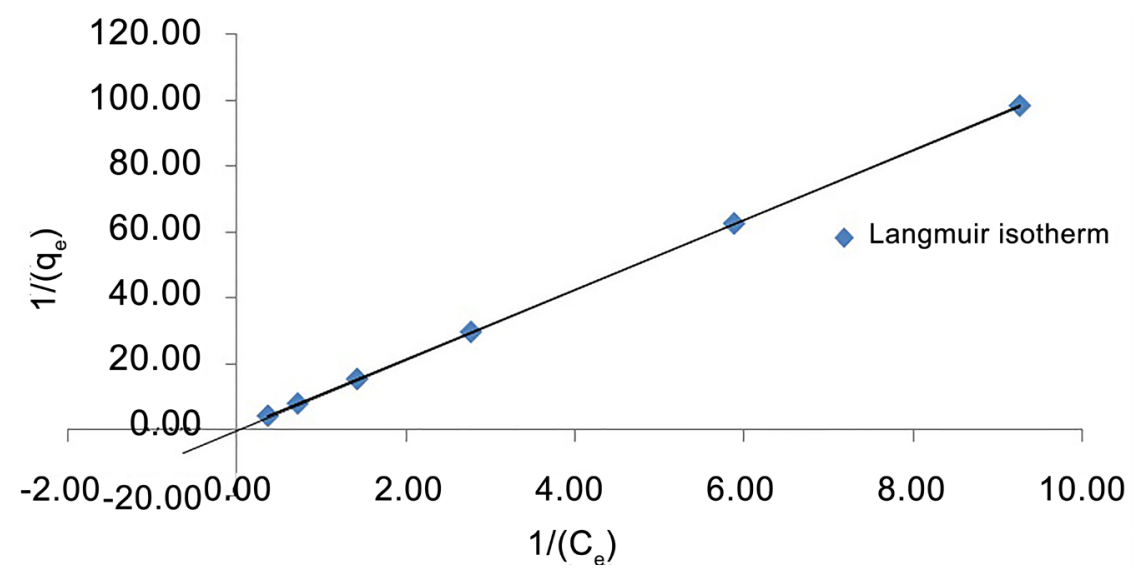

Figure 4. Linear Langmuir isotherm equation graph of 1/qe as a function of $1 /$ Ce based on the results of adsorption isotherm experiment from which Langmuir coefficient (constant) and maximum adsorption capacity was obtained. 
$\mathrm{Cr}(\mathrm{Vl})$ on two soils for which no inorganic carbon was detected. This compares with $2.32 \%$ of total Carbon contents including inorganic cabon (Table 1) for the experimental soil in this study, which might be explained due to their lower adsorption capacities. Inorganic carbon $\left(\mathrm{CO}_{2}\right.$ and $\left.\mathrm{HCO}_{3}\right)$ decreases chromate adsorption by competing for non-specific adsorption sites [37] [38] [39].

\subsubsection{Effect of Ionic Strength on Cr(VI) Adsorption Isotherms}

Chromium (VI) adsorption edges in KCI electrolyte solutions indicated that higher ionic strength resulted in less $\mathrm{Cr}(\mathrm{VI})$ adsorption. Less $\mathrm{Cr}(\mathrm{VI})$ was adsorbed when electrolyte concentration was increased in soil. The effect of ionic strength is attributable to two effects: first, direct competition of $\mathrm{Cl}$ ion with $\mathrm{Cr}(\mathrm{VI})$ for oxyhydroxide surface sites [34] and second, decrease in the electrostatic potential near the surface sites [37]. Cr adsorption on the soil reduces site density, and consequently, reduces $\mathrm{Cr}(\mathrm{VI})$ adsorption. The electrostatic potential effect of $\mathrm{C}$ on $\mathrm{Cr}(\mathrm{VI})$ adsorption can be attributed to the effect of the surface potential on $\mathrm{Cr}(\mathrm{VI})$ surface complexation reactions [32].

\subsection{Environmental Perspective}

Results of this study can be extended to the assessment of the associated possible environmental challenges. The following aspects should be considered for the prevention of possible environmental impacts that might be caused by the presence of $\mathrm{Cr}(\mathrm{VI})$ in various environmental compartments;

\subsection{1. $\mathrm{Cr}$ (VI) Reduction to $\mathrm{Cr}(\mathrm{III})$}

The study has shown that $\mathrm{Cr}(\mathrm{VI})$ is a major environmental concern amongst all $\mathrm{Cr}$ states, while $\mathrm{Cr}(\mathrm{III})$ is the most stable of all. Furthermore, it has been revealed that reduction of $\mathrm{Cr}(\mathrm{VI})$ to $\mathrm{Cr}(\mathrm{III})$ is the best method of dealing with environmental impacts of $\mathrm{Cr}(\mathrm{VI})$ in soils.

\subsubsection{Cr(VI) Adsorption}

It was also shown that adsorption of $\mathrm{Cr}(\mathrm{VI})$ is the second best method of reducing environmental consequences related with hexavalent chromium in soil. Although this process retains the species of toxic hexavalent chromium in the soil but it can be used as a temporary remedial towards minimizing the presence of chromium in the soil.

\subsection{3. pH Effect}

As it has been observed in this study, that an increase in $\mathrm{pH}$ favors oxidation of chromium (III) to toxic chromium (VI) and vice-versa, then the increase in soil $\mathrm{pH}$ has negative environmental impact to the soil while the decrease in soil $\mathrm{pH}$ is beneficial to our environment. So, our soils should be kept at low $\mathrm{pH}$ to avoid chromium related environmental impacts to both plants and animals.

\subsubsection{Solute Concentration Effect}

It has also been observed, the increase in solute concentrations favors adsorption of the solute in the soil, which promotes the availability of harmful chromium to 
clean soils. This causes an increase in the amount of $\mathrm{Cr}(\mathrm{VI})$ in the environment resulting into possible negative environmental impacts. Therefore, release of $\mathrm{Cr}(\mathrm{VI})$ to the environment must be restricted.

\subsubsection{Ionic Strength Effect}

As it has been shown in this study, the presence of other metallic ions in the soil decreases the adsorption of $\mathrm{Cr}(\mathrm{VI})$ due to direct competition of the adsorption site on soil surface. This makes $\mathrm{Cr}(\mathrm{VI})$ species available on soil surface that may later be leached to contaminate groundwater systems or remain available for consumption by plants and animals. On the other hand, less ionic strength offers less competition and more $\mathrm{Cr}(\mathrm{VI})$ will be adsorbed in the soil, which is also unfriend to the environment. To control the effect of this factor there must be other soil minerals/materials such as organic matters that may force reduction of the available hexavalent chromium species in the soil.

\section{Conclusion}

Results from this study show that adsorption and reduction are major reactions accounting for removal of $\mathrm{Cr}(\mathrm{VI})$ from soil solution. While adsorption is low under the conditions present in this soil, reduction potential is high. The reduction process is highly time-dependent and continues until the reduction capacity of the soil is attained. In a nutshell, chemical reactions, such as reduction, strongly influence chromium mobility in soil. Adsorption kinetics experiments indicated that $\mathrm{Cr}(\mathrm{VI})$ removal from soil solution increases with increasing solute concentration, with decreasing $\mathrm{pH}$ and with decreasing ionic strength. Adsorption reactions reached equilibrium within 12 hours in batch reactors. Increasing background electrolyte concentration (KCI) decreased $\mathrm{Cr}(\mathrm{VI})$ adsorption on soil. The adsorption isotherm of $\mathrm{Cr}(\mathrm{VI})$ for this soil conforms well to the Langmuir isotherm at constant $\mathrm{pH}$. Two $\mathrm{Cr}(\mathrm{VI})$ adsorption parameters: the maximum sorption capacity $\left(\mathrm{Q}_{\mathrm{o}}\right)$ and Langmuir adsorption constant $\left(\mathrm{K}_{\mathrm{L}}\right)$, were determined as $1.0135 \times 10^{-4} \mathrm{~mol} / \mathrm{g}$ and $0.0622 \mathrm{mg} / \mathrm{L}$, respectively.

\section{References}

[1] Nriagu, J.O. and Pacyna, J.M. (1988) Quantitative Assessment of Worldwide Contamination of Air, Water and Soils by Trace Metals. Nature, 333, 134-139. https://doi.org/10.1038/333134a0

[2] Kotas, J. and Stasicka, Z. (2000) Chromium Occurrence in the Environment and Methods of Its Speciation. Environmental Pollution, 107, 263-283. https://doi.org/10.1016/S0269-7491(99)00168-2

[3] Richard, F.C. and Bourg, A.C. (1991) Aqueous Geochemistry of Chromium: A Review. Water Research, 25, 807-816. https://doi.org/10.1016/0043-1354(91)90160-R

[4] Mwegoha, W.J. and Lema, M.W. (2016) Effectiveness of Activated Groundnut Shells to Remove Chromium from Tannery Wastewater. International Journal of Environmental Monitoring and Protection, 3, 36-42.

[5] United States Environmental Protection Agency (1998) Toxicological Review of Hexavalent Chromium. National Centre for Environmental Assessment, Office of Research and Development, Washington DC. 
[6] Ryan, M.P., Williams, D.E., Chater, R.J., Hutton, B.M. and McPhail, D.S. (2002) Why Stainless Steel Corrodes? Nature, 415, 770-774. https://doi.org/10.1038/415770a

[7] Das, N. and Matthew, L. (2011) Chromium Pollution and Bioremediation: An Overview. In: Khan, M.S., Zaidi, A., Goel, R. and Musarrat, J., Eds., Biomanagement of Metal-Contaminated Soils, Springer Science + Business Media B.V., Dordrecht, 297-321.

[8] Grabarczy, M., Korolczuk, M. and Tyszczuk, K. (2006) Extraction and Determination of Hexavalent Chromium in Soil Samples. Analytical and Bioanalytical Chemistry, 386, 357-362.

[9] Salunkhe, P.B., Dhakephalkar, P.K. and Paknikar, K.M. (1998) Bioremediation of Hexavalent $\mathrm{Cr}$ in Soil Microcosms. Biotechnology Letters, 20, 749-751.

https://doi.org/10.1023/A:1005338820430

[10] Jeyasingh, J. and Philip, L. (2005) Bioremediation of Chromium Contaminated Soil: Optimization of Operating Parameters under Laboratory Conditions. Journal of Hazardous Materials, 118, 113-120. https://doi.org/10.1016/j.jhazmat.2004.10.003

[11] World Health Organization (1998) Chromium Environmental Health Criteria. WHO, Geneva.

[12] Yolcubal, R. and Akyol, N.H. (2007) Retention and Transport of Hexavalent Chromium in Calcareous Karst Soils. Turkish Journal of Earth Sciences, 16, 363-379.

[13] Zayed Adel, M. and Terry, N. (2003) Chromium in the Environment: Factors Affecting Biological Remediation. Plant and Soil, 249, 139-156.

https://doi.org/10.1023/A:1022504826342

[14] Sharma, D.C. and Pant, R.C. (2003) Chromium Uptake Its Effects on Certain Plant Nutrients in Maize (Zea mays L. CV. Ganga 5) 1994. Journal of Environmental Science and Health, Part A, 29, 941-948. https://doi.org/10.1080/10934529409376085

[15] Shanker, A.K., Cervantes, C., Loza-Tavera, H. and Avudainayagam, S. (2005) Chromium Toxicity in Plants. Environment International, 31, 735-753. https://doi.org/10.1016/j.envint.2005.02.003

[16] Nieboer, E. and Jusys, A.A. (1988) Biologic Chemistry of Cr. In: Nriagu, J.O. and Nieboer, E., Eds., Chromium in the Natural and Human Environments, John Wiley \& Sons, New York, 21-80.

[17] Zayed, A., Lytle, C.M., Qian, J.H. and Terry, N. (1998) Chromium Accumulation, Translocation and Chemical Speciation in Vegetable Crops. Planta, 206, 293-299. https://doi.org/10.1007/s004250050403

[18] Katz, S.A. and Salem, H. (1994) The Biological and Environmental Chemistry of Chromium. VCH Publishers, Inc., New York.

[19] Chandra, P., Sinha, S. and Rai, U.N. (1997) Bioremediation of Cr from Water and Soil by Vascular Aquatic Plants. In: Kruger, E.L., Anderson, T.A. and Coats, J.R., Eds., Phytoremediation of Soil and Water Contaminants, ACS Symposium Series 664, American Chemical Society, Washington DC, 274-282.

[20] Cheng, S. (2003) Heavy Metal Pollution in China: Origin, Pattern and Control. Environmental Science and Pollution Research, 10, 192-198.

https://doi.org/10.1065/espr2002.11.141.1

[21] Li, Z., Ma, Z., van der Kuijp, T.J., Yuan, Z. and Huang, L. (2014) A Review of Soil Heavy Metal Pollution from Mines in China: Pollution and Health Risk Assessment. Science of the Total Environment, 468, 843-853.

[22] Chen, J. (2007) Rapid Urbanization in China: A Real Challenge to Soil Protection 
and Food Security. Catena, 69, 1-15.

[23] Chang, L.Y. (2003) Alternative Chromium Reduction and Heavy Metal Precipitation Methods for Industrial Wastewater. Environmental Progress, 22, 174-182. https://doi.org/10.1002/ep.670220315

[24] Noh, H.J., Lee, M.G., Lee, H.S., Kim, M., Kim, D. and Kim, T.S. (2012) A Study of Interference Factor of Analysis Method of Hexavalent Chromium in Soil Using UV/VIS Spectrometry and Application of Ion Chromatography. Journal of Soil and Groundwater Environment, 17, 33-42. https://doi.org/10.7857/JSGE.2012.17.6.033

[25] Loveland, P.J. and Whalley, W.R. (2000) Particle Size Analysis. In: Smith, K.A. and Mullins, C.E., Eds., Soil Analysis-Physical Methods, Marcel Dekker, New York, 281314. https://doi.org/10.1201/9780203908600.ch7

[26] Cameron, D.A. and Klute, A. (1977) Convection Dispersion Solute Transport with a Combined Equilibrium and Kinetic Adsorption Model. Water Resources Research, 13, 183-188. https://doi.org/10.1029/WR013i001p00183

[27] Schroth, H.M. (1989) A Kinetic Solute Transport Model for the Movement of Chromium(Vl) through Soils. Department of Civil Engineering, Oregon State University, Corvallis.

[28] Stollenwerk, K.G. and Grove, D.B. (1985) Adsorption and Desorption of Hexavalent Chromium in an Alluvial Aquifer near Telluride, Colorado. Journal of Environmental Quality, 14, 150-155. https://doi.org/10.2134/jeq1985.00472425001400010030x

[29] Bartlett, R.J. and Kimble, J.M. (1976) Behavior of Chromium in Soils: 1. Trivalent Forms II. Hexavalent Forms. Journal of Environmental Quality, 5, 379-386.

[30] Bartlett, R.J. and James, B.R. (1988) Mobility and Bioavailability of Chromium in Soils, in Chromium in the Natural and Human Environments. John Wiley Sons, New York.

[31] Azizian, M.F. and Nelson, P.O. (1993) Experimental Evaluation and Chemical Modeling of Hexavalent Chromium Adsorption, Desorption and Reduction in a Natural Soil. Thesis of PHD, Department of Civil Engineering, Oregon State University, Oregon.

[32] Zachara, J.M., Ainsworth, C.C., Cowan, C.E. and Resch, C.T. (1989) Adsorption of Chromium by Subsurface Soil Horizons. Soil Science Society of American Journal, 53, 418-428. https://doi.org/10.2136/sssaj1989.03615995005300020018x

[33] Griffing, R.A., Au, A.K. and Frost, R.R. (1977) Effect of pH Hydrogenion Concentration on Adsorption of Chromium from Landfill-Leachate by Clay Minerals. Journal of Environmental Science and Health. Part A: Environmental Science and Engineering, 12, 431-449. https://doi.org/10.1080/10934527709374769

[34] Bartlett, R.J. (1991) Chromium Cycling in Soils and Water: Links, Gaps and Methods. Environmental Health Perspectives, 92, 17-24.

[35] Amuda, O.S., Giwa, A. and Bello, I.A. (2007) Removal of Heavy Metal from Industrial Wastewater Using Modified Activated Coconut Shell Carbon. Biochemical Engineering Journal, 36, 174-181. https://doi.org/10.1016/j.bej.2007.02.013

[36] Mesuere, K. and Fish, W. (1992) Chromate and Oxalate Adsorption on Goethite. 1. Calibration of Surface Complexation Models. Environmental Sciences and Technology, 26, 2357-2364. https://doi.org/10.1021/es00036a004

[37] Davis, J.A. and Leckie, J.O. (1980) Surface Ionization and Complexation at the Oxide/Water Interface 3. Adsorption of Anions. Journal of Colloid and Interface Science, 74, 32-43. https://doi.org/10.1016/0021-9797(80)90168-X

[38] Barcelona, M.J. and HoIm, T.A. (1991) Oxidation-Reduction Capacity of Aquifer 
Solids. Environmental Science and Technology, 25, 1565-1572.

https://doi.org/10.1021/es00021a006

[39] Palmer, C.D. and Wittbrodt, P.R. (1990) Geochemical Characterization of the United Chrome Products Site. Final Report, Environmental Science and Engineering, Oregon Graduate Institute, in: CH2MHill, Inc.: United Chrome Products Superfund Site, Phase II.

\section{Scientific Research Publishing}

Submit or recommend next manuscript to SCIRP and we will provide best service for you:

Accepting pre-submission inquiries through Email, Facebook, LinkedIn, Twitter, etc. A wide selection of journals (inclusive of 9 subjects, more than 200 journals)

Providing 24-hour high-quality service

User-friendly online submission system

Fair and swift peer-review system

Efficient typesetting and proofreading procedure

Display of the result of downloads and visits, as well as the number of cited articles

Maximum dissemination of your research work

Submit your manuscript at: http://papersubmission.scirp.org/

Or contact gep@scirp.org 